Interior, the Bureau of Mines and the El Paso Natural Gas Company, was the first attempt to scale up this procedure with a nuclear explosion.

A 26 kiloton device was exploded near Farmington, New Mexico, on December 10 last year at a depth of 4,200 feet, well below the maximum depth for conventional gas mining, and it produced a chimney in the rock with almost exactly the dimensions that had been predicted. The chimney, with a volume of at least two million cubic feet, formed as the roof of a chamber created by the explosion fell in. Gas has since flowed into the chimney through fractures created by the explosion. Large scale tests of the gas began on June 28, when production was started at a rate of five million cubic foet a day. After eleven days the well was closed for measurements of temperature and pressure and reopened for four days, flowing at a rate of 0.75 million cubic feet a day. During these last four days the pressure in the chimney increased by between 10 and $20 \mathrm{lb}$ per sq. in. absolute, so the flow of gas into the chimney must exceed the 0.75 million cubic feet a day which was being taken out.

The first gas tapped in June contained 36 per cent of carbon dioxide, believed to have been formed by the decomposition of carbonates during the explosion, but the proportion of carbon dioxide decreased progressively as the proportion of hydrocarbons increased. The gas has been continuously monitored for radioactive isotopes ; the explosion should have generated several radionuclides including krypton-85, iodine-131, xenon-133 and tritium. Field tests of small samples of gas taken on January 10 , only a month after the explosion, revealed xenon-133, but this isotope has a half life of only $5 \cdot 3$ days and by June it had disappeared. On the other hand, both krypton-85 and tritium were detected in June but at levels which the AEC claims "do not constitute a health hazard". Samples of gas have been taken to the Lawrence Radiation Laboratory in California for detailed analysis, and a fuller evaluation of the whole project is promised for a meeting of the Society of Petroleum Engineers in Houston in September. It is clear, however, from the preliminary data that the sponsors think Gasbuggy has been a success, and if it lives up to present expectations the technique could more than double the US national reserves of natural gas. Whether or not it proves to be an economically viable method remains to be seen; Gasbuggy has cost about $\$ 4.7$ million.

\section{Planning the Environment}

THE Centre for Environmental Studies (CES) has just produced a report on its first year's work. It is too early yet to see solid results ; the centre's principal effort has been devoted to surveying its domain and deciding which projects to support. It is now sponsoring a wide programme of studies at various institutions and universities in Britain.

When building, transport and habits of work and leisure are allowed to react in an uncontrolled way, the result is a confusion of interests to which the inconvenience of many large cities bears witness. Although the design of cities and transport systems may depend in the last resort on value judgments. the grounds for making such decisions can often be strengthened, and any arbitrary components made to stand out more clearly, by a variety of logical and mathe- matical techniques. The discipline which the CES was founded to promote could broadly be described as the application of operations research to the problems of urban planning. Successful instances of this technique include the transport models worked out for several American cities; the models allow prediction to be made of future trends, on the basis of which action. can be taken to invalidate or fulfil the prediction.

The CES was conceived at a conference held in Cambridge in 1965 and sponsored by the British Ministry of Housing and Local Government and the Ford Foundation of New York. With five year grants of $\$ 750,000$ from the Ford Foundation and $\mathfrak{E} 600,000$ from the British Government, the centre started work in April 1967. Its purpose is to "promote research and education into the planning and design. of the physical environment". A research staff under the direction of A. H. Chilver, professor of civil and municipal engineering at University College, London, has been at work assessing fruitful areas of study.

The centre has now made grants to initiate or continue the support of 17 projects. A three year grant has been made to Sir Leslie Martin and Mr Lionel March at Cambridge University who are studying which forms of building make the most efficient use of land-skyscrapers, happily, are not the only solution. Professor Garnett at Sheffield is looking into the social and economic consequences of setting more stringent limits to pollution of the air and noise. The kind of result that may emerge from this study is a calculation of the rate of return on an investment which reduces pollution levels. The largest single grant, $£ 45,000$ for three years, has been awarded to Dr Michael Young and Mr Peter Wilmott at the Institute of Community Studies; they are studying the patterns of family work and leisure and the way in which these are relevant to planning.

During its first year the CES has invested $£ 35,000$ in external research. This sum is expected to build up to $£ 250,000$ a year by 1972 . In the course of its survey of research needs, the CES found no lack of good ideas to support. Its criteria for investing funds include an assessment of the relevance of a project to major planning problems; studies which are of an essentially development nature are considered to be the concern of government departments and planning authorities.

Besides supporting external research, the centre aims to act as an international forum for the discussion of planning problems. A series of seminars beginning later this year will cover such topics as population growth and movement, leisure activities, and transport studies.

\section{National Parking}

A National Park Day Centre at Brockhole, Windermere, the first of its kind in the country, is to be opened to the public next summer. The centre, owned by the Lake District Planning Board, is in a delightful setting about half-way between the road and the lake on the main Kendal-Keswick road. The gardens and grounds cover 32 acres including 6 acres of woodlands and a third of a mile of lakeshore. At the moment the board is converting the house, which was once a con. valescent home, into a centre where visitors to the lakes can go for educational material of all kindsmaps, models, books and exhibits relating to the 
topography, history, natural history, rural economy and general culture of the Lake District. Lectures and demonstrations are also planned.

The board bought Brockhole in 1966 with the help of a grant, but there was a long delay before doing anything with it because of the financial squeeze. At long last, authority to go ahead with the development and management of the centre was given by the Government in November 1967. Now the board is trying to find a director for the centre. The salary offered, initially in the range $£ 1,725-£ 2,105$, may be considered low by national standards, but the board hopes that the situation of Brockhole and other amenities will more than compensate for this. The authority to go ahead with the scheme was given under section 86 of the National Parks Act, 1949. This act, however, has been superseded by the new Countryside Act, 1968,

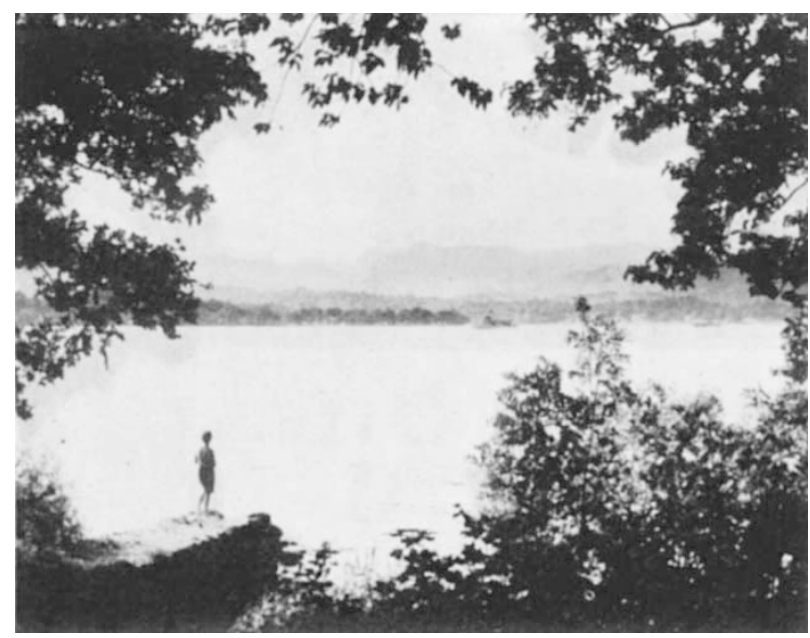

National Park Centre at Brockhole, Windermere. (Photo: G. V. Berry.)

which came into force on August 3. In effect the act confers "new powers on local authorities and other bodies for the conservation and enhancement of natural beauty and for the benefit of those resorting to the countryside ...". The National Parks Commission has been disbanded in favour of a Countryside Commission which has additional powers and duties, although in practice it has very little more executive powers than its predecessor. One of the most important proposals is that local authorities now have considerable powers to set up country parks for recreation. These should relieve the pressure on the National Parks, which are increasingly suffering from the demands of the motor car.

On the question of access, the new act extends the type of land on which access agreements may be negotiated from the mountain, heath and foreshore of the 1949 act to include rivers, canals and woodlands. Statutory water undertakings and the Forestry Commission have increased powers to provide for recreation on reservoirs and in forests. Of particular interest to the Lake District is the provision which allows local planning authorities to make by-laws for the control of boating on National Park lakes. Inclusion of such a clause was made at the committee stage in the House of Lords and it should be effective in dealing with nuisance and damage from boats.
Noise, a problem suffered particularly seriously at Windermere, should also come within the scope of this clause.

\section{Millom to Close}

The Millom Hematite Ore and Iron Company, where the first commercial spray steelmaking plant was put into operation, is to close. The announcement last week said that the costs of making pig iron at Millom were now above the current prices, in part because of cheap imports from Russia and East Germany. Competition with the British Steel Corporation is also a problem for small independent producers, and Millom has been making losses for some months.

The decision is a particularly sad one, because Millom was the only British firm willing to try out the spray steelmaking techniques developed by the British Iron and Steel Research Association. A pilot plant was built at Millom which has now been in production for some eighteen months, and which has proved the feasibility of the technique outside the laboratory. Without Millom, the technique might still be a laboratory curiosity, as BISRA scientists frankly admit. As it is, the success of the plant at Millom has encouraged Lancashire Steel to build a plant at its works at Irlam, and Shelton Iron and Steel Co. is also building a spray steel plant. BISRA has set up a wholly owned subsidiary company, Spray Steelmaking Limited, to market the process in partnership with Humphreys and Glasgow, the chemical engineering company.

Millom's attempts to become steelmakers were never very popular in official circles. The Iron and Steel Board refused in January 1967 to give Millom sanction to raise $£ 1$ million for an expansion plan based on the spray technique, arguing that there were no grounds for increasing the total productive capacity of British steelworks when many of the works were operating well below full capacity. In any case, the official view has always been that production should be concentrated in as few large centres as possible, in order to make the most of economies of scale. The spray technique, which costs very much less to install than does traditional steelmaking equipment, reduces the force of this argument. Finally, the Iron and Steel Board gave grudging approval for the plan to go ahead, but it seems that spray steelmaking came too late to save Millom.

The decision to close will come as a severe shock to the town of Millom, which relies almost exclusively on the ironworks. Just over 1,000 people will be made redundant by the closure, in an area which already has more than its share of unemployment. In the past, Millom has not always been included in the north-west development area, which has made it harder to attract new industry, and it seems certain that many of those made redundant will have to move away from the area to find work.

Although this is a poor reward for showing the way with the new process, spray steelmaking itself seems to be making good progress. The process, in which pig iron is atomized by a blast of oxygen and is converted to steel as it falls into a receiving ladle, does not feature in the immediate development plans of the British Steel Corporation, but the workers at the BISRA laboratories are confident of its long-term importance. 